\title{
Mediterranean precipitation and its relationship with sea level pressure patterns
}

\author{
Roy Thompson and David N. Green \\ School of GeoSciences, The University of Edinburgh, U.K.
}

\begin{abstract}
The relationship between Mediterranean precipitation and North Atlantic and European sea level pressure fields has been studied using statistical techniques to investigate the variability within the data. A principal component analysis shows the major winter precipitation variability is described by a see-saw fluctuation between the Western and Eastern Mediterranean. The pressure-precipitation relationships indicate that a highly variable, pressure region situated to the south of Britain dominates this major precipitation pattern. The large-scale pressure fields which facilitate the precipitation patterns have been isolated using a canonical correlation analysis. Although the well-known major pressure centres of action in the North Atlantic are important, pressure changes in the east are found to also control the transport of moisture across the Mediterranean to a large degree, as the presence of a large high over Kazakhstan causes meridonial flow and impedes the passage of moisture across the Mediterranean. The pressure-precipitation relationships are found to be very consistent over multi-decadal, seasonal, monthly and daily time-scales with trajectory analysis confirming many of the features of the average seasonal pressure charts. This steadiness and regularity indicates that the Mediterranean precipitation teleconnection is a robust phenomenon that is affected by large-scale pressure changes to both the east and west.
\end{abstract}

Key words Mediterranean-precipitation - principal component - canonical correlation - trajectory

\section{Introduction}

The Mediterranean is characterised by hot, dry summers and warm, wet winters. The winter precipitation variability patterns of the Mediterranean region, which extends $3600 \mathrm{~km}$ from the Iberian Peninsula in the west to Israel in the east, show marked differences between the north-western and the south-eastern areas (e.g., Conte et al., 1989; Douguedroit, 1998).

Mailing address: Prof. Roy Thompson, School of GeoSciences, The University of Edinburgh, Grant Institute, The King's Buildings, West Mains Road, Edinburgh EH9 3JW, U.K.; e-mail: roy@ed.ac.uk
This variability can be described as a teleconnection; an anti-correlation between the rainfall in Iberia and that in the Near East.

What influences the operation of the Mediterranean precipitation teleconnection? Convergence of moisture and regional precipitation is controlled by the dominant atmospheric pressure structures. The major sources of water close to the Mediterranean region are the Atlantic Ocean, the Mediterranean Sea itself, and further east the Arabian Sea. Consequently pressure systems over the North Atlantic, Europe and North Africa must all be considered in answering the above question. Hurrell (1995) has shown that changes in the North Atlantic pressure system, indicated by extremes of the North Atlantic Oscillation (NAO), strongly alter the moisture transport across the Atlantic Ocean and onto the European landmass. The NAO is a measure of a pressure teleconnection and is defined as a large-scale al- 
ternation of atmospheric mass between regions of subtropical high pressure (the Azores high) and subpolar low pressure (the Icelandic low) in the North Atlantic (e.g., Lamb and Peppler, 1987). The NAO can be expected to contribute to explaining the dominant variations in the Western Mediterranean (e.g., Zorita et al., 1992; Storch et al., 1993; Rodo et al., 1997; Trigo and Palutikof, 2001), however there may well be other pressure systems influencing the precipitation in the Mediterranean Basin.

The spatio-temporal precipitation patterns of local regions within the Mediterranean have been described in some detail. Good summaries of precipitation and its relationships with circulation are available for the Central (Maheras et al., 1992; Bordi et al., 2001; Bordi and Sutera, 2002), Northwestern (Zhang et al., 1997; Ulbrich et al., 1999) and Eastern (Kuteil and Paz, 1998; Kuteil et al., 2002) Mediterranean. These studies point to the importance of both regional and local topographic influences. Here we include analyses of the less well-studied areas of Northern Africa, so increasing the geographical coverage, and concentrate on Mediterranean wide effects. We are primarily concerned with long-term (multi-decadal) changes and variability and so only analyse sites with published precipitation data that extend as far back as at least 1905. The main objective of this paper is to study the extent and temporal behaviour of Mediterranean precipitation patterns and their relation to sea level pressure situations over Europe and the North Atlantic. The main techniques employed are canonical correlation and principal component analysis.

\section{Methodology}

An overview of the steps employed in our analyses is given in the flow chart of fig. 1 . Monthly values of precipitation for stations around the Mediterranean region spanning the time period 1905-1990 were obtained from the Global Historical Climatology Network Database (Vose et al., 1992). The winter months, December through to March, were chosen for study as these are the classic months for Mediterranean precipitation and because more

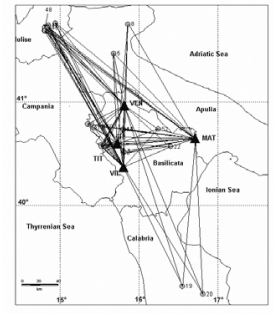

Fig. 1. The major stages of the analysis. $\mathrm{GHCN}=$ $=$ Global Historical Climatology Network; $\mathrm{CRU}=\mathrm{Cli}-$ mate Research Unit, University of East Anglia.

pronounced precipitation and pressure variability occurs in the winter season (Hurrell, 1995). Sites were selected on the basis of completeness of the records and on the need to achieve a wide geographical spread. Forty-four satisfactory sites were found. We consider this data set to be the best obtainable, providing a good balance between geographical extent, completeness and series length.

The collection of long-term precipitation data is fraught with difficulties and many records are discontinuous, due to either a break in recording or a change of recording site. Missing data can cause severe problems in correlation and time-series analysis. This is especially true for the statistical techniques used in this project, principal component analysis and canonical correlation analysis, as both require complete data sets.

15100 mean monthly precipitation values were available to us, however on account of the long time period under analysis there were inevitably many missing values. To form com- 
plete records an imputation was executed. The most conservative approach is to use the mean of the available data. However we have fair correlation between the mean monthly precipitation at nearby sites ( $r^{2}$ typically 0.55$)$ and so a less conservative approach was preferred. We considered different geographical regions separately and then used a median polish technique (Velleman and Hoaglin, 1981) to estimate the missing data month by month. In practice for regions with poor site correlation (e.g., North Africa; $r^{2} \sim 0.3$ ) our interpolation method will give results similar to using the time-series mean, while for regions with good spatial coherence (e.g., Iberia; $\left.r^{2} \sim 0.8\right)$ results will be similar to those obtainable by multiple regression. The solid circles in fig. $2 c$, d are typical examples of our imputation. Missing monthly means for two recent years were imputed for Lisbon, while missing data for eight war years and one recent year were imputed for Limassol.

The winter monthly mean-sea-level pressure data were obtained on the $5^{\circ}$ latitude by $10^{\circ}$ longitude grid of Jones (1987). We selected data extending from $50^{\circ} \mathrm{W}$ to $60^{\circ} \mathrm{E}$ and from $20^{\circ} \mathrm{N}$ to $65^{\circ} \mathrm{N}$ covering the North Atlantic, Eu-
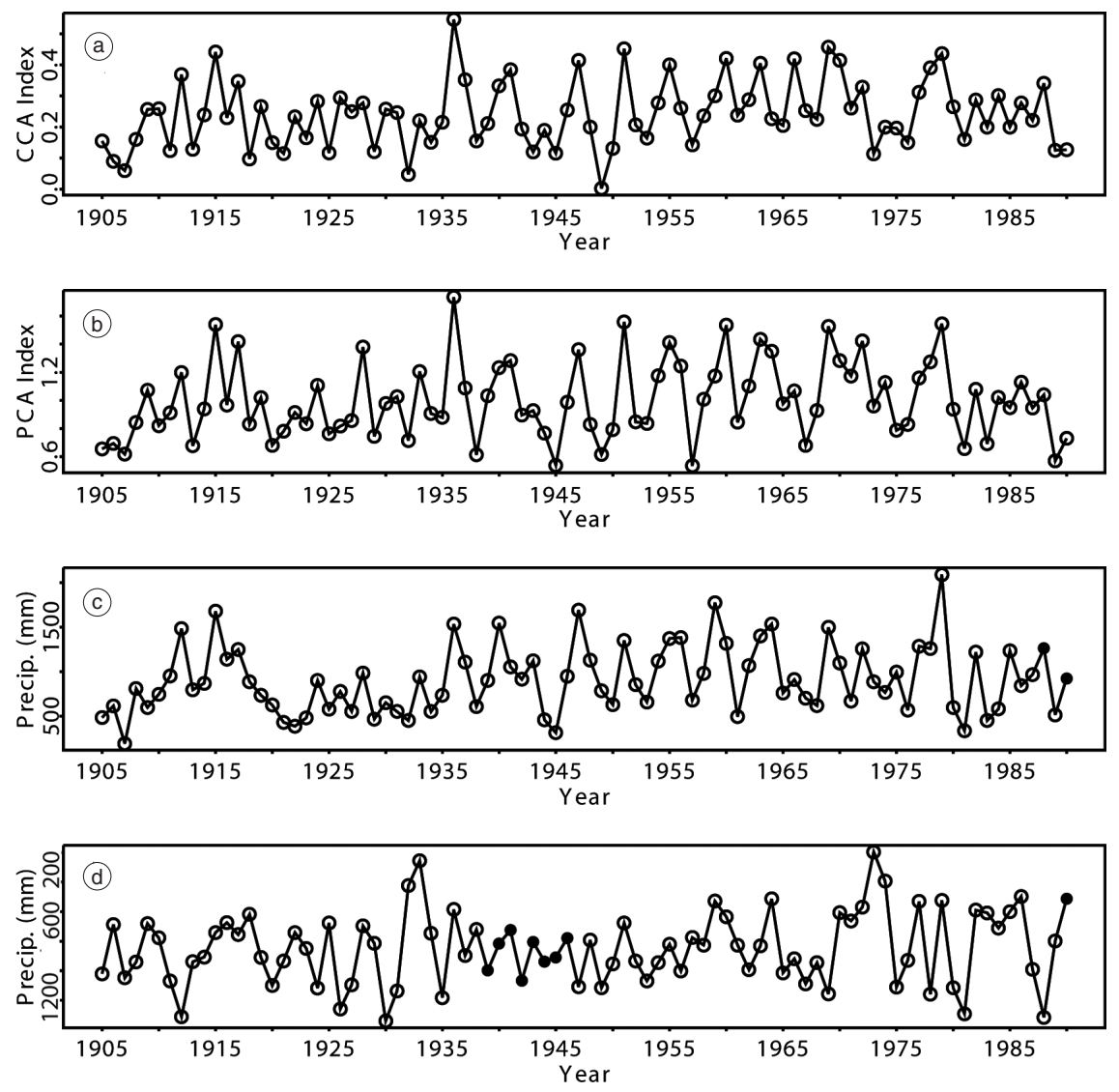

Fig. 2a-d. a) The 1st canonical function (precipitation) index. b) The 1st precipitation principal component index. c) The precipitation record at Lisbon, Portugal. d) The precipitation record (scale inverted) at Limassol, Cyprus. 
rope, North Africa and the western extent of Asia. The data were initially checked for outlying values, which were removed. The pressure data grid was almost complete $(<1 \%$ data missing) and any outliers were replaced using the imputation scheme outlined above.

To allow comparison between individual station records for both sets of data a normalisation is required to remove the bias due to some regions having larger mean values for the variables than others. As we are only concerned in the variability of precipitation and pressure, dividing each record through by the mean value of that time-series provides a simple normalisation with the advantage that all values are still positive reducing problems in the subsequent analysis. It should be noted that the normalised pressure and precipitation variables still have different ranges. In particular the coefficient of variation (standard deviation of time-series/ arithmetic mean of time-series) is approximately two orders of magnitude larger for the precipitation data compared to that of the pressure data. This causes no mathematical problems in the subsequent analyses except that certain values, as noted in the text below, are not directly comparable.

The two data sets are moderately large and therefore for an efficient analysis they required a reduction in size, whilst maintaining the maximum information content possible. Principal Component Analysis (PCA) provides the ideal candidate for such data compression (e.g., Jolliffe, 1990) and was applied individually to both the precipitation and pressure data sets. PCA worked well on our two data sets allowing us to study only the first four principal components of the pressure data and the first three principal components of the precipitation data. The dimensions of the analysis were considerably reduced and yet $83.5 \%$ of the pressure variance and $51.2 \%$ of the precipitation variance was retained.

To gain insight into the relationship between the two sets of data, pressure and precipitation, a Canonical Correlation Analysis (CCA) was performed. CCA quantifies the strength of the relationship between two data sets by maximising the correlation between linear combinations of the variables (e.g.,, Hair et al., 1995). The problem is to find the linear combination of precipitation variables that has maximum correlation with a linear combination of pressure variables. To simplify proceedings it is beneficial to use the two data sets in their principal component co-ordinates. From the CCA a time-series can be constructed which emphasises the years at which the pressure and precipitation patterns are highly or inversely correlated. We also found it helpful to consider only the six most extreme years, for both the high and low canonical function values. For these extreme years mean pressure maps were constructed. These maps can be easily interpreted, alongside meteorological records, to show which large scale features of the pressure field give rise to the Mediterranean precipitation teleconnection. Storch and Zwiers (1999, p. 382) provide us with a formal definition of a teleconnection pattern. The mean pressure maps can also be compared with maps of individual events (see Section 3.3).

It is important to emphasise that a statistical analysis based solely on principal component and canonical correlation analysis basically only serves to show that patterns of the analysed fields covary. By itself it does not demonstrate the patterns of major statistical weight are dynamically significant (being, for example, linear or non-linear normal modes); not that there is a cause and effect connection between the covarying variables; or that the dominant patterns of co-variation (as identified, by the canonical correlation analysis) are dynamically significant. So in addition to analysing mean monthly data, daily and sub-daily records were studied for specific synoptic conditions. The daily records chosen for comparison with the mean monthly charts were selected as objectively as possible. The year and month of an event were selected from the exceptionally high and low values of the first CCA timeseries. The day of the event was chosen as that with the highest rainfall at either Lisbon (Portugal) or Paphos (Cyprus), depending on which polarity of the precipitation teleconnection was being considered. Lisbon and Paphos were chosen to represent typical West and East Mediterranean sites respectively.

Surface pressure maps were constructed to give a synoptic overview of the conditions over 
Europe, at the time of the precipitation event, and back and forward trajectories were produced using the British Atmospheric Data Centre trajectory service to give an indication of the direction and speed of airflow towards and away from the two sites. For this analysis an initial pressure level of $700 \mathrm{mb}$ was chosen over the two recording stations as a compromise corresponding very approximately to an average height of precipitation formation while being removed from surface boundary layer levels. The height along the trajectory path was calculated from the pressure level data using the hypsometric equation.

\section{Results}

\subsection{The Mediterranean precipitation teleconnection}

A spatial view of the Mediterranean precipitation teleconnection is provided by the 1 st PCA loadings map (fig. 3) giving an indication of the geographical extent of the first-order precipitation variability. The zero loading line trends south-west to north-east, with the loading size increasing with distance from the zero contour. The time series of the first principal component (fig. 2b) indicates how the variability in the precipitation across the Mediterranean, shown in fig. 3 , has changed over the 85 year timespan since 1905. The PCA index is centred on a value of one, therefore high index years such as 1936 show unusually high precipitation in the west and low rainfall in the east, whereas low index years such as 1989 show the reverse situation. The index shows a slight tendency to rising values prior to the 1960 s/1970s, and falling values thereafter.

\subsection{CCA and the synoptic pressure situations}

The canonical correlation analysis took the precipitation PCA discussed above and a PCA of the corresponding pressure field and calcu-
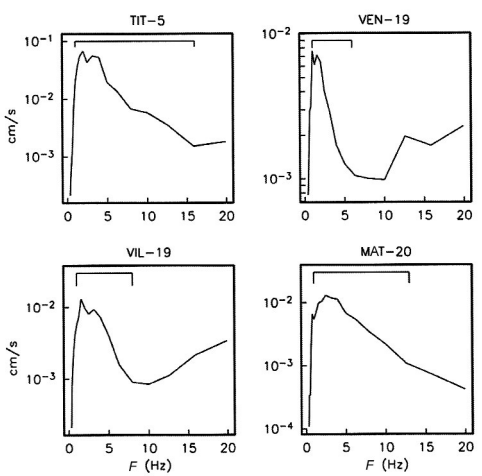

Fig. 3. The geographical form of the 1 st precipitation principal component. The contours represent equal component loading values and indicate that the regions of maximum variability occur towards the west and southeast extents of the Mediterranean. The smooth contours were drawn by fitting a lowess smoothing function (Cleveland, 1979) to the loadings of the first principal component. Black dots represent the forty-four precipitation recording stations used in the analysis. 
lated the strength of the relationship between the two sets. The resulting time series (fig. 2a) is centred on a value of 0.24 , and shows the variability of the first canonical function. This CCA time series is extremely well correlated with the precipitation first principal component $(r=0.86)$, giving an indication that the precipitation teleconnection is highly influenced by the pressure situation.
The geographical patterns of the CCA showing the positions of maximum response between the variability in the pressure and precipitation fields over the 85 year study are shown in fig. 4a,b. The first precipitation canonical function is remarkably similar to the first precipitation principal component indicating that the predominant Mediterranean precipitation variability is well correlated with the pressure changes over
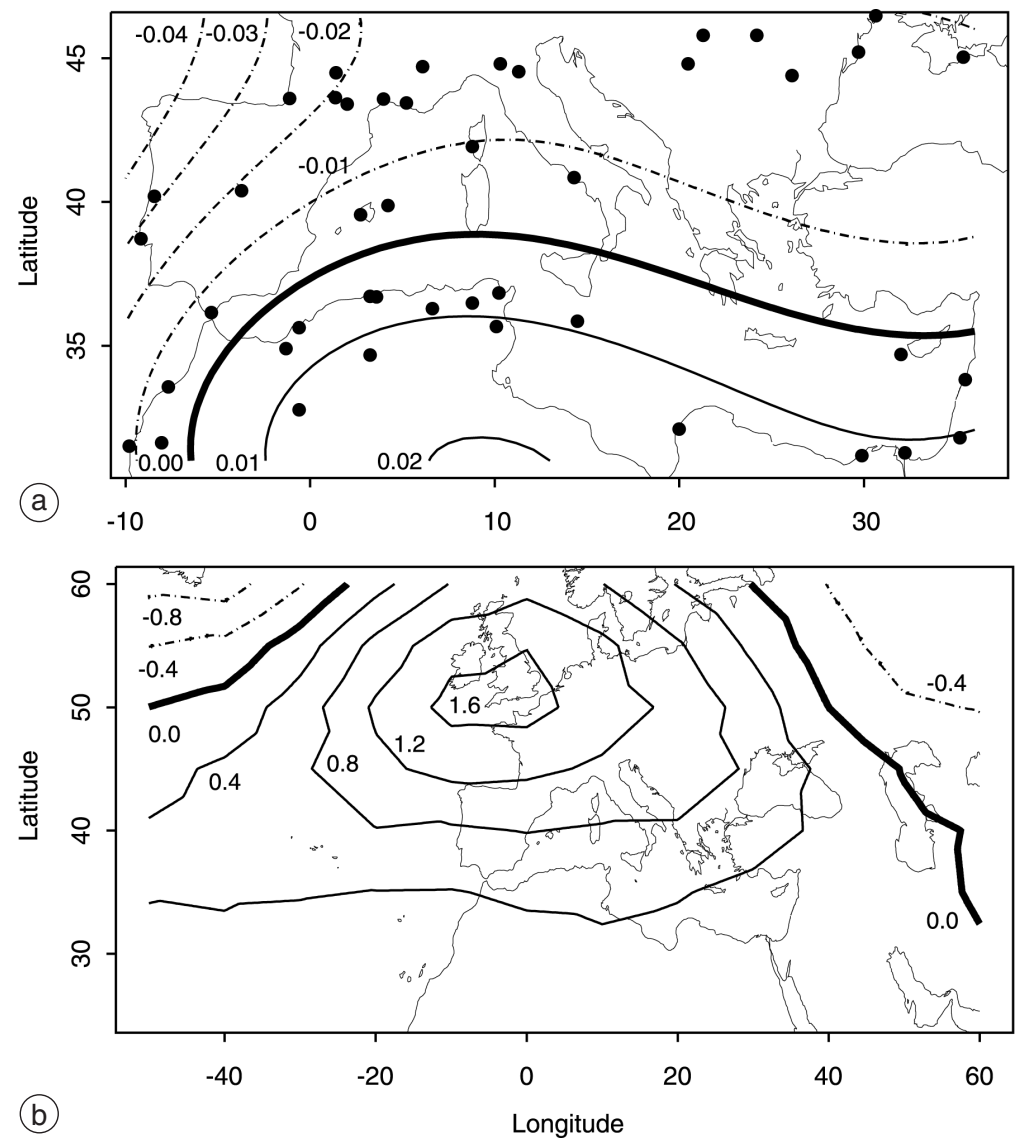

Fig. 4a,b. a) The geographical form of the first precipitation canonical function. The contours indicate equal loading values. Increasing loading values represent increased correlation between the variations of precipitation at that locality and the pressure field. b) The geographical extent of the first pressure canonical function. The contours indicate equal loading values. Increasing loading values represent increased correlation between the variations of pressure at that locality and the whole precipitation field. Thus regions of high loading are particularly responsive. N.B.: the loading values in a) and b) are not directly comparable due to the choice of normalisation (see text for further details). 


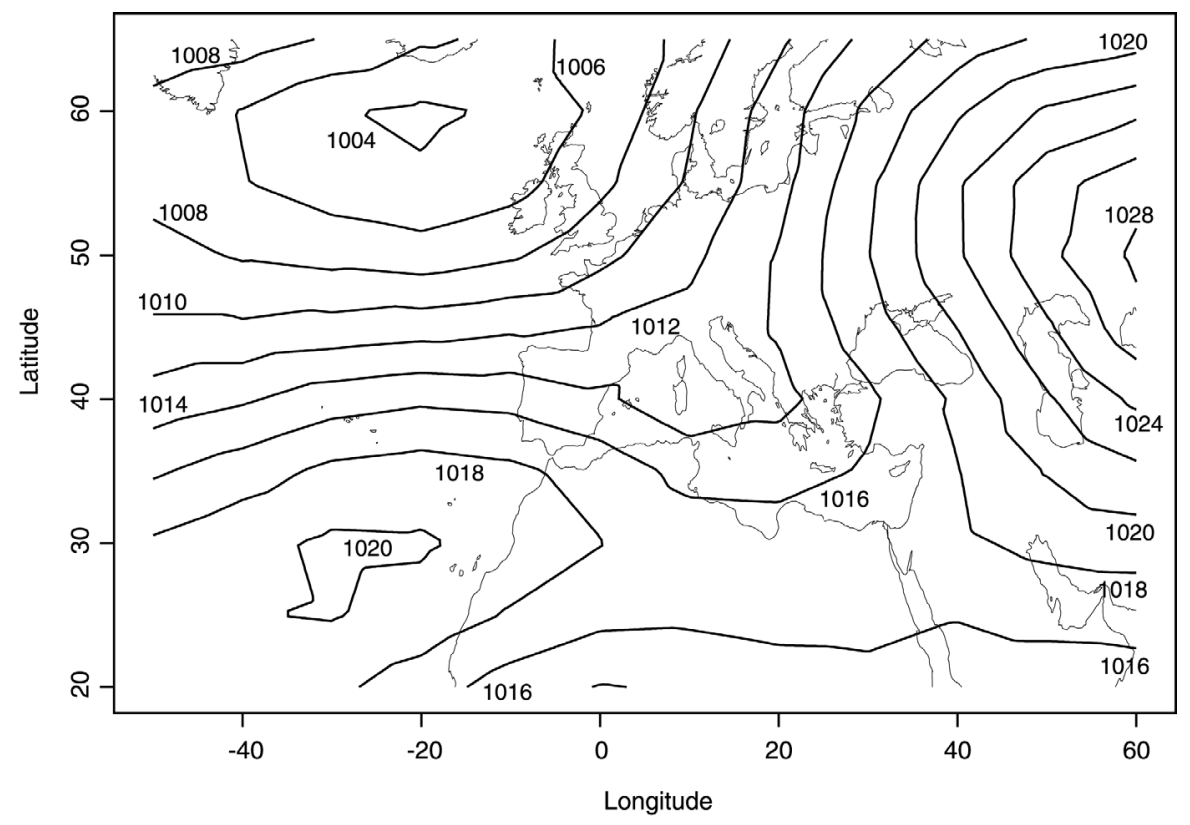

Fig. 5a. The mean winter pressure map associated with the six highest canonical function years (precipitation in the west, dry in the east). All contours labelled in millibars.

the area chosen. The first pressure canonical function map indicates in which regions the pressure variability contributes most to the precipitation changes. The form of the canonical function is at first sight unexpected. Rather than two centres of action over the East and West Mediterranean or a single maximum lying in between the two foci of precipitation variability, major regions of pressure variation well to the north are found. One elongated focus, centred at an approximate position of $80^{\circ} \mathrm{N}$ and $10^{\circ} \mathrm{W}$, extends from South Greenland across the North Pole to Northern Russia. It is similar in shape to the area of high correlation between Portuguese rainfall and North Atlantic sea level pressure as given by Ulbrich et al. (1999), but with a promontory extending towards Siberia. The negative polarity of loadings indicates that pressure variations in a high index year (wet in the west/dry in the east) will tend to be unusually high pressure over Greenland and over Northern Russia. The second focus is situated over the approaches to the English Channel (fig. 4a,b) and is of opposite (i.e. positive) polarity indicating that the pressure variations in this area are anticorrelated with those to the north. In high index years higher pressure than usual over the English Channel guides maritime air and precipitating weather systems north westwards away from Iberia.

The form the canonical function takes can be clarified by examining the six most extreme years for both polarities of the index. Figure $5 a, b$ plots the mean winter sea-level pressure maps for these two sets of extreme conditions. Figure 5a presents the situation causing high precipitation in the Western Mediterranean and low precipitation in the east. The Azores high and Icelandic low pressure systems are displaced south of their mean positions causing a series of isobars to run west-east directly across the Iberian Peninsula, providing a route for moisture from the Atlantic Ocean to impinge upon Spain and Portugal. Towards the east of the Mediterranean, a large high-pressure ridge (a western bulge of the Siberian high-pressure 


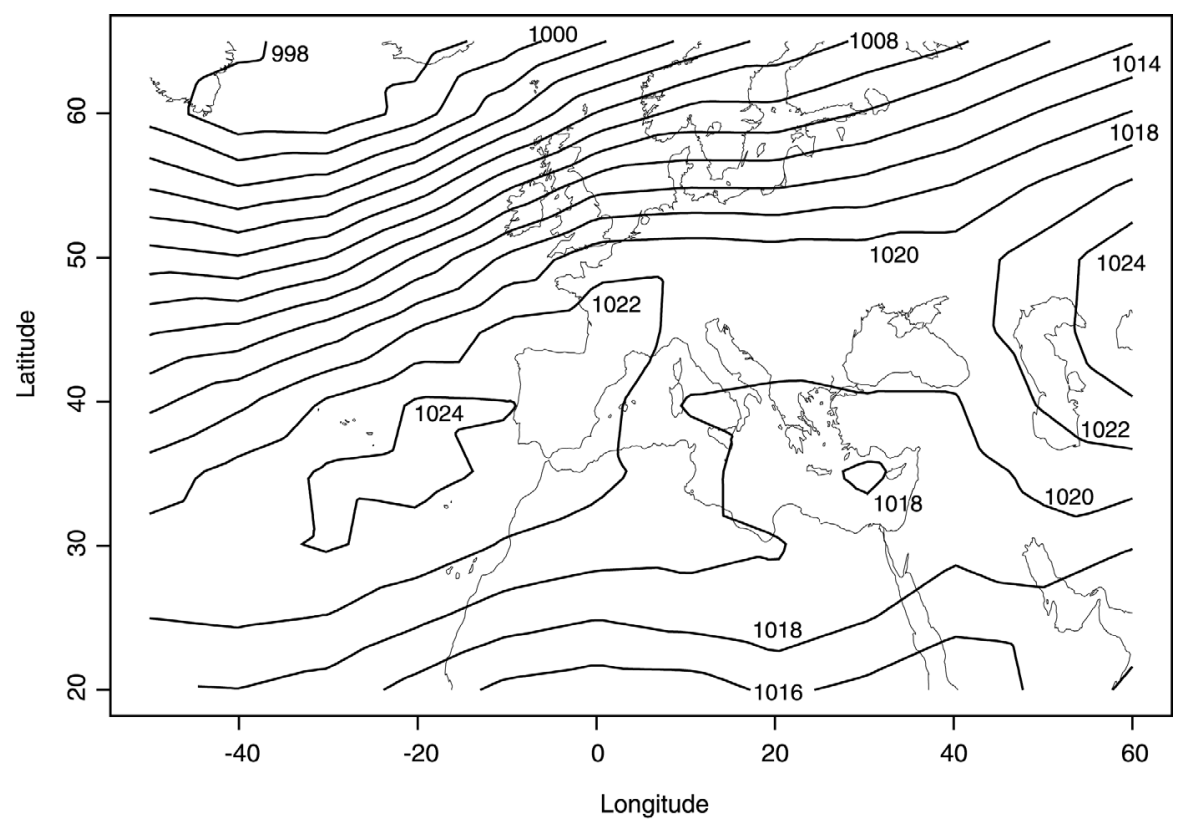

Fig. 5b. The mean winter pressure map associated with the six lowest canonical function years (precipitation in the east, dry in the west). All contours labelled in millibars.

system), referred to here as the Kazakhstan high, provides a block causing meridional airflow. The col on the ridge between the Azores and Kazakhstan highs lies to the south of the Mediterranean over Libya.

Figure $5 \mathrm{~b}$ indicates the situation leading to increased precipitation in the east and dry conditions in the west. The Azores high pressure system is displaced to the north and extends over the Iberian Peninsula preventing airflow across the Atlantic and onto the western Mediterranean where below normal precipitation is recorded. Consequently tight isobars trend north eastwards from the Atlantic across Northern Scotland and then onwards across Scandinavia and Finland. Situated in the eastern Mediterranean is a distinct pressure minima, the Cyprus low. This region has been linked to Mediterranean cyclones (Alpert et al., 1990), the associated cyclonic flow causes high precipitation in Israel and the surrounding area (e.g., Zangvil and Druian, 1990). Further east the Kazakhstan high is more subdued and dis- placed somewhat to the south. The ridge between the Azores and Kazakhstan highs now lies to the north of the Mediterranean with a broad col over Hungary and Romania.

\subsection{Individual events}

In addition to examining the 6-year mean winter circulation of the extremes of our Mediterranean precipitation teleconnection, we have also analysed individual precipitation events to see how the sub-daily dynamic situation compares to the long-term average.

A high rainfall event recorded in Lisbon on 27th January 1979 was chosen as an example of behaviour in a year of high CCA index. January 1979 was wet across Iberia and dry, or moderately dry, in the Eastern Mediterranean (completely dry at Cairo). The synoptic pressure map, trajectory path and trajectory height for this one event can be seen in fig. 6a. The pressure map for 26th January 1979 (the 24-h peri- 

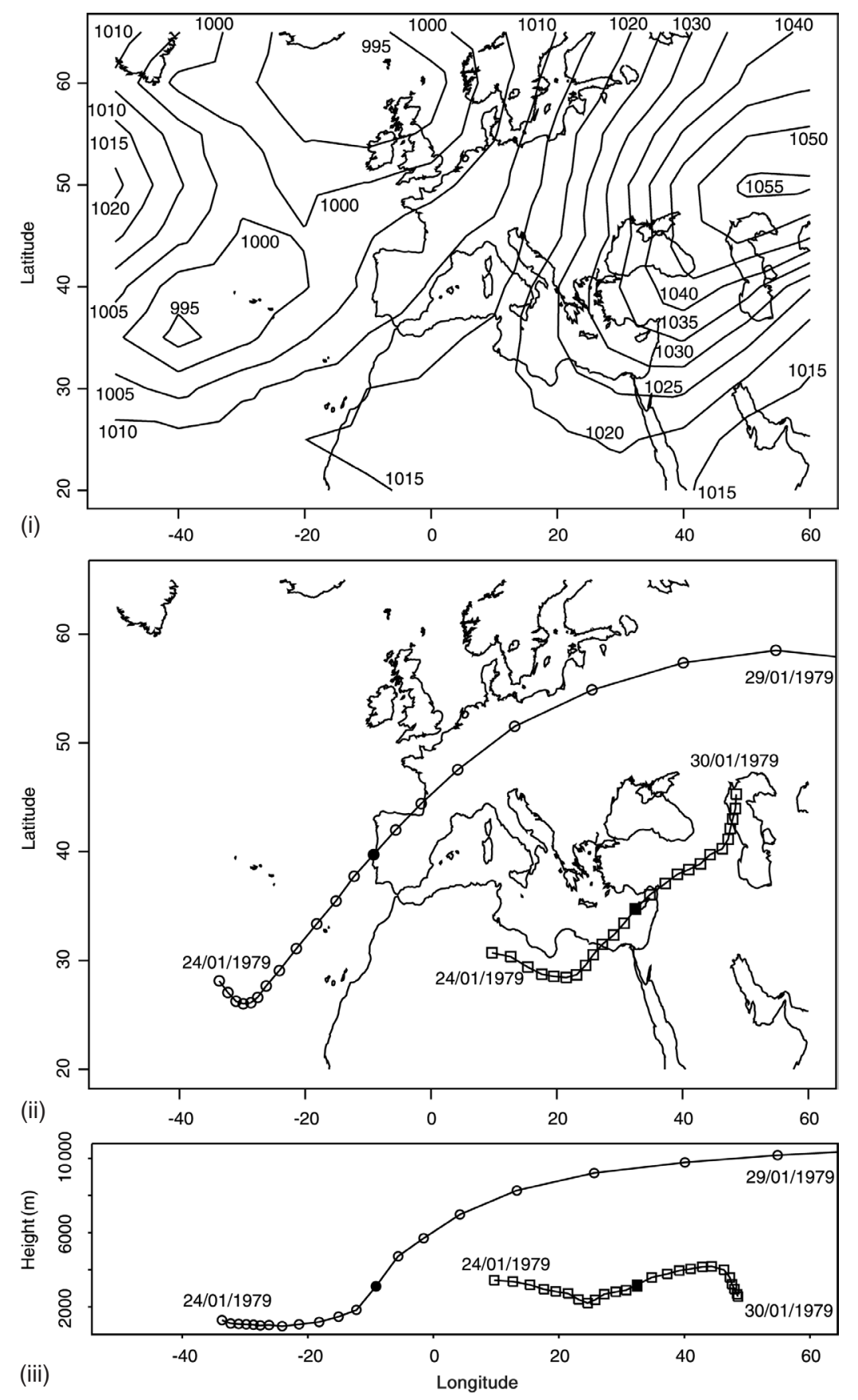

Fig. 6a. i) The pressure map for 26th January 1979. ii) The forward and back trajectories for the $700 \mathrm{mb}$ level at Lisbon (crosses) and Paphos (open circles). The markers are placed at 6 hourly intervals. iii) The trajectory heights for Lisbon (crosses) and Paphos (open circles). Solid symbols 00:00 on 27/01/1979. 

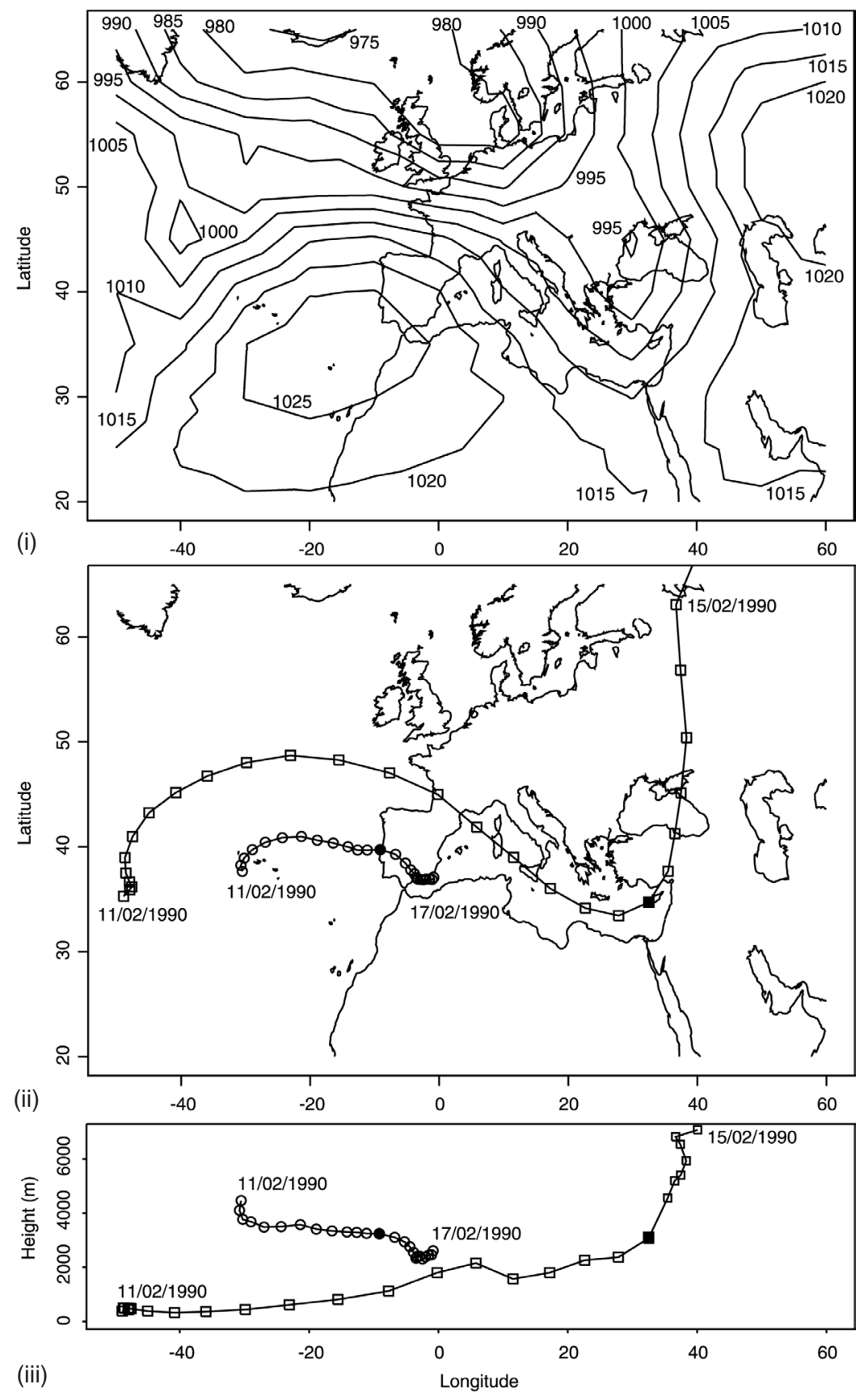

Fig. 6b. i) The pressure map for the 13th February 1990. ii) The forward and back trajectories for the $700 \mathrm{mb}$ level at Lisbon (crosses) and Paphos (open circles). The markers are placed at 6 hourly intervals. iii) The trajectory heights for Lisbon (crosses) and Paphos (open circles). Solid symbols 00:00 on 14/02/1990. 
od leading up to the precipitation event) shows a well formed high in the east extending from Kazakhstan restricting the Mediterranean airflow and generating anticyclonic circulation across the Eastern Mediterranean Sea. The Icelandic low pressure system and the Azores high are displaced much further to the south than their mean positions so allowing depressions to pass across the Atlantic along more southerly tracks than normal onto the Iberian peninsula. The 26th sees lows passing over the Canaries and the Faeroes and a cold front approaching Lisbon. The 3-day back trajectory for Lisbon shows cyclonic circulation and rising air arriving from the SW (ii and iii in fig. 6a). The trajectory is consistent with rainfall in Lisbon and with the air passing low over the Atlantic gathering moisture before rising to condense and precipitate over the land. The forward trajectory from Lisbon shows the air continuing to ascend and being carried north-west away from the Mediterranean illustrating how the moisture from the Atlantic does not reach Israel or Cyprus in such high index years.

The corresponding trajectory path for $\mathrm{Pa}$ phos, Cyprus for the same six-day period shows dry air circulating around the northern edge of an anticyclone before being transported off the Sahara and passing towards the north-east. The flow corresponds well with the winter trajectories studied by Dayan (1986).

Turning to a low canonical function year. Paphos experienced a high rainfall event on the 14th February 1990 (fig. 6b). The pressure map shows a large area of high pressure centred over the Canaries and extending over the Iberian Peninsula with depressions crossing to the north of Scotland and a low pressure system extending into the eastern Mediterranean. There is a high pressure system to the east extending from the Persian Gulf to Kazakhstan, however this is much smaller than in the example above. A series of lows pass through the East Mediterranean around this time. One formed over North Italy on the 11th and during the 13th to 15 th another passed to the north of Cyprus, an associated cold front producing the torrential rain in Paphos on the 14th. The trajectory paths show air movement consistent with this pressure situation. Air crossing the Atlantic is forced around the high pressure system, passing over the Bay of Biscay into the Western Mediterranean. This air has been at a low height across the ocean gathering up water, as it passes into the Mediterranean it rises slowly until it reaches approximately $3000 \mathrm{~m}$ over Cyprus, becoming the source for the precipitation event.

The air passing over the Iberian Peninsula at this time also travels across the Atlantic, however it moves slowly and descends as it reaches land due to it being trapped within the Azores high pressure system. This descending air has no potential for precipitation.

\section{Discussion}

\subsection{Pressure influences on the teleconnection}

The principal component analysis shows that the Mediterranean precipitation teleconnection is the dominant form of precipitation variability across the whole region in the winter months. The canonical correlation analysis provides two synoptic pressure situations that give a first order explanation of this variability.

High precipitation in the Western Mediterranean occurs due to the moisture transport off the North Atlantic impinging upon the western seaboard of North Africa and Iberia. This is a direct consequence of the southward shift of the Icelandic low and Azores high pressure systems (fig. 5a) comparable to the motions described in the work of Sahsamanoglou (1990). At the same time, the Kazakhstan high provides a block for any westerly airflow across the Mediterranean, forcing meridional flow northwards over Eastern Europe and Russia and allowing the Eastern Mediterranean to remain dry. The meridional flow causes air temperatures to be some $1.5^{\circ} \mathrm{C}$ warmer than average in the region extending from Rumania to Eastern Turkey. At the same time, in North Europe, a zone extending from Iceland across the Northern Baltic to Northern Russia experiences air temperatures $1.5^{\circ} \mathrm{C}$ below average. These temperature anomalies further demonstrate the regional extent and consistency of the pressure pattern producing the Mediterranean precipitation teleconnection. 
Conversely with an extended high pressure system over the Iberian Peninsula, as in fig. 5b, Spain and Portugal remain dry as moisture carried off the Atlantic is advected north westwards onto Northern Europe. Air temperatures some $2.0^{\circ} \mathrm{C}$ above normal are produced over much of Sweden and North Finland by the flow from the south-west. In contrast air temperatures over Eastern Turkey are some $2.0^{\circ} \mathrm{C}$ cooler than average. The isobars surrounding the extended Azores high exhibit some curvature across Northern Europe leading to the possibility of moisture entering the Eastern Mediterranean either by transportation from the Atlantic or from secondary depressions formed within Mediterranean areas in the lee of the Alps (e.g., Buzzi and Tibaldi, 1978). The trajectory of fig. 6bii indicates that the former occurred on the 13th of February 1979. The Cyprus low in fig. 5b indicates that depressions and cyclonic flow are present in the East which remove considerable heat and moisture from the water (Shay-El and Alpert, 1991). This is illustrated by the rising airmass in the trajectory of fig. $6 \mathrm{~b}$ as it approaches the Cyprus region.

The areas of pressure variability which affect the precipitation teleconnection most are highlighted by the large loading regions in the first canonical correlation map (fig. 4b). The central area of high variability correlation, centred over the English Channel approaches, is linked to the translation of the Azores high pressure system. The English Channel centre of action is the position that is affected most by this movement. When the Azores high is prominent and moves northward from its mean position (approximately $30^{\circ} \mathrm{N}$ and $35^{\circ} \mathrm{W}$ : Sahsamanoglou, 1990) this region underlies high pressure (e.g., fig. 5b) but when the Azores high and the Icelandic low move southwards the region is overlain by a low-pressure system. As explained above this alters the moisture transport across the Iberian Peninsula. As this variability affects the movement of moisture into and across the Western Mediterranean, so the pressure variability in Northern Russia affects the eastern end of the teleconnection. As the pressure increases in Northern Russia the Kazakhstan high blocks any East Mediterranean storm tracks and airflow across the Mediter- ranean (fig. 5a). This coincides with the southward migration of the Azores high causing low pressure to be present in the English Channel. This difference in pressure between the western and eastern centres of action is illustrated by the difference in polarity between the canonical function loadings of the two centres of action in fig. 4b. A year in which there is unusually high pressure in Northern Russia corresponds to a year of unusually low pressure in the English Channel approaches. The opposite situation occurs when the Kazakhstan high wanes and the Azores high strengthens and pushes northward over the English Channel region.

Calculation of the canonical function pair of fig. 4a,b involves a long series of matrix manipulations including scaling, extraction of principal components and estimation of canonical loadings. The whole sequence is then followed in reverse to generate the individual canonical components. A very instructive exercise, which can be used to confirm that the above matrix algebra has been performed correctly, is to subtract the pressure field of fig. 5a (the six highest index years) from that of fig. $5 b$ (the pressure field of the six lowest index years). Here the result, as expected, is an almost identical pattern to that of fig. $4 \mathrm{~b}$.

Recently Palutikof et al. (1996) and Quadrelli et al. (2001) have investigated the relationship between Mediterranean precipitation and $500 \mathrm{hPa}$ geopotential height. Although Quadrelli et al.'s (2001) results only spanned 17 years, and so they were in doubt about the long-term robustness of their results, our 85year sea level pressure/precipitation relationships are in excellent agreement with their linkages to large-scale upper-air circulation anomalies. By contrast, Palutikof et al. (1996) emphasise the $500 \mathrm{hPa}$ surface over the Mediterranean Sea itself as an indicator of atmospheric pressure which relates to Mediterranean precipitation variability.

\subsection{The second canonical pair}

The second canonical pair highlights the major correlation between the pressure and rainfall data sets under the constraint that this 
correlation is orthogonal to the first canonical pair. The second precipitation canonical function has high loadings over the North African sites and loadings close to zero over Portugal to the west and Israel to the east. The area of high loadings is centred over the region in which there is most difference between the first principal component (fig. 3) and the first precipitation canonical function (fig. 4a). This can be explained due to the fact that the second canonical function, which perturbs the consistency between the canonical function and the principal component is describing a second order effect. The first canonical function has a $r^{2}$ value of 0.79 while the second has a $r^{2}$ value of only 0.22 .

The second pressure canonical function shows that the area of large pressure changes which is predominantly correlated with the second-order precipitation variation in North Africa is situated well to the north of the Mediterranean, with a centre over Northern Scandinavia. The zero contour of the map of this second pressure canonical function passes along the whole length of the Mediterranean Sea. So again, we find it is the broad regional or far field, pressure variations that principally orchestrate Mediterranean precipitation variability.

\subsection{The link between monthly and daily analyses}

The pressure charts in fig. 5a,b are the average of six mean winter (DJFM) pressure charts chosen due to their high or low canonical index value. Therefore, they are an extremely smoothed version of the actual pressure situation at any particular time within the winter period. Nevertheless the main pressure patterns are robust, representative features. For example the low-pressure centre that lies between Crete and Cyprus, in fig. 5b, occurs as a closed contour feature in three out of the four individual winter months (December through March). A distinctive, closed contour, Eastern Mediterranean low is also present in five of the six individual winters that were averaged to make up fig. 5b. Furthermore the mean pressure charts of fig. 5a,b can be compared with the pressure maps and tra- jectory analyses of fig. 6a,b that shows plots representing actual events. These type events show broadly similar features to those of the monthly analysis.

The most important dynamical features consistent with high precipitation in the west and low precipitation in the east are the high over Kazakhstan linked with low pressure over the Atlantic, both of which are present in the daily chart (fig. 6a). This situation causes a strong east-west pressure gradient and air to flow off the ocean onto the Iberian Peninsula, before it passes north as the block creates meridonal flow. The equivalent air mass passing over Cyprus at the same time has its origins in the dry regions of the Northern Sahara. The back trajectory stays at an approximately constant height allowing no advection of moisture. Dayan (1986) classified this type of flow as of 'inland North African type'.

Consistency between the seasonal mean and daily charts is also apparent for the opposite situation in which the Eastern Mediterranean is subject to higher rainfall. The high pressure over Portugal in fig. $6 \mathrm{~b}$ causes the Atlantic moisture to travel north and then turn around the pressure maximum and back into the Mediterranean. The low pressure system then extends into the eastern region generating cyclonic flow and transportation of moisture over Israel, Cyprus and coastal regions of Egypt. Thus as discussed by Zangvil and Druian (1990) rainfall over Israel is largely affected by the trajectory of air prior to the rain event. Maritime air trajectories are linked with rain events. However, our canonical pressure patterns would suggest that flow from the Atlantic is also of importance in addition to Zangvil and Druian's (1990) postulated source as moisture evaporation from the Mediterranean. At these times there is also airflow across the Atlantic onto Lisbon, however it is travelling extremely slowly within the high pressure system and is sinking as it passes over the land (fig. 6biii), thereby allowing no precipitation. Once again the fact that the same features can be identified in both the seasonal average and daily synoptic charts suggests that a stable recurrent phenomenon orchestrates the Mediterranean precipitation teleconnection. 


\subsection{Mediterranean precipitation and pressure teleconnections}

It has been well documented by previous workers that the NAO causes precipitation anomalies in the Western Mediterranean area (e.g., Lamb and Peppler, 1987; Hurrell, 1995). However, the present study indicates that pressure variability in the east, far removed from the North Atlantic, has a large influence on the passage of moisture through the entire Mediterranean region. The relative importance of the Kazakhstan high and Cyprus low have possibly been previously underestimated in terms of their effect on Mediterranean precipitation. The moisture which forms the precipitation comes from the west as seen in all the trajectories (fig. $6 a, b)$, however it is the presence of a block or weakened anticyclone in the east which determines the extent of any meridonial flow, and therefore the extent of any Eastern Mediterranean precipitation. The influence of this eastern precipitation can be seen clearly on the time series (fig. 2a-d). Comparing the CCA index (fig. 2a) to the two individual precipitation records (fig. 2c and 2d) it can be seen that different temporal sections have distinct features from one or either of these rainfall time-series. For example the variation in the PCA index (fig. 2b) around 1945 closely follows that of the Lisbon precipitation record whereas the variation around 1970 has more in common with the Paphos time series, these variations can then be followed into the CCA time-series.

Rodgers (1997) suggests that the NAO has little influence on the North Atlantic storm tracks and that the major changes in these tracks are consistent with sea level pressure changes in the Bay of Biscay region. This part of the Atlantic is identifiable in fig. $4 \mathrm{~b}$ as having a large influence on the passage of moisture from the Atlantic into the Mediterranean, as seen by our 'English Channel' centre of action centred slightly northwards of Rodgers' in the Bay of Biscay. When there is low pressure over the Bay of Biscay (fig. 5a), the Azores high is pushed to the south allowing moisture to pass over the Atlantic and onto the Iberian Peninsula causing high precipitation. High pressure over the Bay of Biscay extends across Spain and Portugal re- ducing the precipitation in this area. The storm tracks from the Atlantic in this situation pass to the north of the Bay of Biscay and then turn south into the Mediterranean, as seen by the trajectories in fig. 6b. The influence of pressure changes over the Bay of Biscay is described in terms of a series of North Atlantic teleconnections summarised by Rodgers (1990). Recently Kutiel and Benaroch (2002) have identified and described the upper level atmospheric teleconnection pattern (NCP) at the $500 \mathrm{hPa}$ level between the North Sea and the Caspian areas as the most significant in the European area. The associated circulation patterns are found to have a major and direct impact on the mean surface air temperature over the Eastern Mediterranean. However the impact of the NCP on rainfall is more complex (Kutiel et al., 2002).

The strength of our canonical correlation between Mediterranean precipitation variability and the large scale pressure field over an 85 year period, coupled with a very similar relationship on annual, monthly and even daily time-scales, suggest it is a robust phenomenon that would be worth investigating further. In particular more work needs to be done on the influence of pressure variations in the east, including the Siberian high, before a complete picture of the link between Mediterranean precipitation and sea-level pressure changes is obtainable. Winter precipitation persists further east through Iraq, Iran, Turkestan and on through Tashkent. However, the precipitation teleconnection patterns are rather weak through this area. To the south winter precipitation patterns change rapidly and there is less scope for additional studies. We were unable to use records on the desert margins (even sites such as Cairo on the Nile Valley proved unworkable) i.e. our analyses in NE Africa were largely restricted to the classic Mediterranean zone which only occupies a very narrow coastal strip where the Libyan and Egyptian deserts encroach on the Mediterranean Sea (Quezel, 1981). The strong canonical pressure loadings over Greenland and Russia, both areas well to the north of the Mediterranean, point to the need of also extending the geographical coverage of the sea-level pressure variations and precipitation patterns northwards. Indeed we have 
subsequently found that winter precipitation along the eastern coast of the Black Sea correlates inversely with precipitation in Northern Spain and Southern France in a very similar fashion to that of the East and West Mediterranean. More speculatively, links with other teleconnections could be explored. Interestingly we find a significant correlation between the first canonical function and the Indian Ocean Dipole. This link, with a pattern of sea surface temperatures within the Indian Ocean (Saji et al., 1999), further suggests that an interaction from the east plays an important role in creating the correct conditions for the Mediterranean precipitation teleconnection. The well-documented Southern Oscillation shows no link with the first canonical function but does have a significant relationship with the second. This connection, harnessed with the knowledge that precipitation over North-west Africa is correlated with the Southern Oscillation (Ropelwski and Halpert, 1987) and that spring precipitation in Spain shows the most significant relationship with the El Niño-Southern Oscillation in Europe (Rodo et al., 1997), suggests that less pronounced Mediterranean precipitation variations may have links with various global pressure phenomena.

\subsection{Statistical identification of pressure influences}

The findings of this paper are based on the identification of correlations between two large data sets. The multivariate statistical methods used provided an extremely powerful tool, allowing clear pictures to be obtained of the variability. The consistency of results throughout are remarkable, with multi decadal (86-year), winter, monthly and daily pressure charts all showing the same broad features and highlighting the phenomena giving rise to the precipitation teleconnection. The consistency is such that even smaller local features such as the Cyprus low are identifiable even on maps of 6year (24-month) winter averages.

Consistency between independent statistical techniques is also found. The first precipitation principal component indicates the major pattern of internal variability within the rainfall data (fig. 3). This produces an extremely similar variability map to that of the first canonical function (fig. 4a), which describes the correlation of the variability between the precipitation and pressure data. These two types of analysis do not necessarily produce the same geographical patterns as the former derives from climatic variability within a climatic parameter, while the later derives from the relationship between parameters.

\section{Conclusions}

The major pattern of precipitation variability in the Mediterranean is shown to be orientated such that it is dipolar with maximum fluctuations in the north-west and south-east. The zero variability line in the first principal component strikes in a south-west/north-east direction separating the Iberian Peninsula and Northern Europe from the Eastern Mediterranean and Northern Africa.

Canonical correlation analysis shows that the European surface pressure field and Mediterranean precipitation field variations are highly correlated with a north-west/south-east precipitation see-saw and an anomalous, highly variable, pressure region situated to the south of Britain.

Pressure maps for the high index years of the canonical function show that a high pressure system over West Kazakhstan causes meridional flow, blocking precipitation from the Eastern Mediterranean. A simultaneous translation of the Azores high to the south allows westerly flow from the Atlantic to pass over the Iberian Peninsula increasing precipitation.

Pressure maps for the low canonical function show the Azores high translated northwards over the Iberian Peninsula, thereby reducing precipitation in the Western Mediterranean. These average pressure maps also indicate the presence of a depression, the Cyprus low, situated in the Eastern Mediterranean. Its location is in good agreement with the findings 
of Zangvil and Druian (1990) who linked the phenomenon with high precipitation in Israel.

The winter pressure and precipitation interaction in the Mediterranean is correlated with the pressure variations across the North Atlantic i.e. the North Atlantic Oscillation. A further link with the Indian Ocean as described by the Indian Dipole Mode is also found to exist.

Our results show excellent consistency between all four individual winter months and the total season (DJFM) over the 86-year period studied, as well as for single precipitation events. The invariability over such a wide range of temporal scales lends confidence to the robustness of the Mediterranean precipitation teleconnection and to its physical link with regional pressure patterns.

\section{Acknowledgements}

The data were obtained from databases kindly provided by P. Jones of the Climate Research Unit at the University of East Anglia, and R. Vose and colleagues of the Global Historical Climatology Network. The British Atmospheric Data Centre is thanked for its reanalysis database and trajectory service. The authors are grateful to Keith Weston who provided much meteorological expertise and advice concerning the synoptic analyses, especially the trajectories.

\section{REFERENCES}

AlPert, P., B.U. NeEman and Y. ShaY-El (1990): Climatological analysis of Mediterranean cyclones using ECMWF data, Tellus, 42A, 65-77

BORDI, I. and A. SUTERA (2002): An analysis of drought in Italy in the last fifty years, Il Nuovo Cimento, 25, 185 206.

Bordi, I., S. Frigio, P. Parenti, A. Speranza and A. SUTERA (2001): The analysis of the standardized precipitation index in the Mediterranean area: large scale patterns, Ann. Geofis., 44 (5/6), 965-978.

Buzzi, A. and S. Tibaldi (1978): Cyclogenesis in the lee of the Alps: a case study, Q. J. R. Meteorol. Soc., 104, 271-287.

Cleveland, W.S. (1979): Robust locally weighted regression and smoothing scatterplots, J. Am. Stat. Ass., 74, 829-836.
Conte, M., A. Giuffrida and S. Tedesco (1989): The Mediterranean Oscillation. Impact on precipitation and hydrology in Italy, in Conference on Climate, Water (Publication of the Academy of Finland, Helsinki), 121-137.

DAYAN, U. (1986): Climatology of back trajectories from Israel based on synoptic analysis. J. Climate Appl. Meteorol., 25, 591-595.

DougueDROIT, A. (1998): Que peut-on dire d'une Oscillation Méditerranéenne?, in «Climate and Environmental Change», Proceedings of the Meeting of the Commission on Climatology of the IGU, Evora, Portugal, 135-136.

HaIR, J.F., R.E. ANDERSON, R.L. TATHAM and W.C. Black (1995): Multivariate Data Analysis with Readings (Prentice Hall, New Jersey), 4th edition, pp. 745.

HurRell, J.W. (1995): Decadal trends in the North Atlantic Oscillation: regional temperatures and precipitation, Science, 269, 676-679.

Jolliffe, I.T. (1990): Principal Component Analysis: a beginner's guide, 1 . Introduction and application, Weather, 45 (10), 375-383.

JONES, P.D. (1987): The early twentieth century Arctic High - fact or fiction?. Climate Dynamics, 1, 63-75.

Kutiel, H. and Y. Benaroch (2002): North Sea-Caspian Pattern (NCP) - An upper level atmospheric teleconnection affecting the Eastern Mediterranean: identification and definition, Theor. Appl. climatol., 71 (1/2), $17-28$.

KuTIEL, H. and S. PAZ (1998): Sea level pressure departures in the Mediterranean and their relationship with monthly rainfall conditions in Israel, Theor. Appl. Climatol., 60 (1/4), 93-109.

Kutiel, H., P. Maheras, M. Turkes and S. Paz (2002): North Sea Caspian Pattern (NCP) - An upper level atmospheric teleconnection affecting the Eastern Mediterranean: implications on the regional climate, Theor. Appl. Climatol., 72 (3/4), 173-192.

LAmb, P.J. and R.A. PePPLER (1987): North Atlantic Oscillation: concept and an application, Bull. Am. Meteorol. Soc., 68 (10), 1218-1225.

Maheras, P., C. Balafoutis and M. Vafiadis (1992): Precipitation in the Central Mediterranean during the last century, Theor. Appl. Climatol., 45, 209-216.

Palutikof, J.P., M. Conte, J. Casimiro Mendes, C.M. GoODESS and F. EsPIRITO SANTO (1996): Climate and climatic change, in Mediterranean Desertification and Land Use, edited by C.J. BRANDT and J.B. THORNES (Wiley, London), 43-86.

QuAdrelli, R., V. PAVAN and F. Molteni (2001): Wintertime variability of Mediterranean precipitation and its links with large-scale circulation anomalies, Climate Dyn., 17, 457-466.

QUEZEL, P. (1981): Floristic composition and phytosociological structure of sclerophyllous matorral around the Mediterranean, in Ecosystems of the World. Mediterranean Type-Shrublands, edited by F. DI CASTRI, D.W. GOODALL and R.L. SPECHT (Elsevier Scientific, New York), vol. 11, 107-121.

RoDGERS, J.C. (1990): Patterns of low-frequency monthly sea level pressure variability (1899-1986) and associated wave cyclone frequencies, J. Climate, 3, 1364-1379.

RoDGERS, J.C. (1997): North Atlantic storm track variability and its association to the North Atlantic Oscillation 
and climate variability of Northern Europe, J. Climate, 10, 1635-1647.

Rodo, X., E. BAERT and F.A. COMIN (1997): Variations in seasonal rainfall in Southern Europe during the present century: relationships with the North Atlantic Oscillation and the El Niño-Southern Oscillation, Climate Dyn., 13, 275-284.

ROPELWSKY, C.F. and M.S. HALPERT (1987): Global and regional scale precipitation patterns associated with the El Niño/Southern Oscillation, Mon. Weather Rev., 115, 1606-1626.

SAHSAMANOGLOU, H.S. (1990): A contribution to the study of action centres in the North Atlantic, Int. J. Climatol. 10, 247-261.

SAJI, N.H., B.N. GosWAMI, P.N. VinAYACHANDRAN and T. Yamagata (1999): A dipole mode in the tropical Indian Ocean, Nature, 401, 360-363.

ShaY-El, Y. and P. AlPERT (1991) A diagnostic study of winter diabatic heating in the Mediterranean in relation to cyclones, Q. J. R. Meteorol. Soc., 117, 715-747.

STORCH, H. vON and F.W. ZwIERs (1999): Statistical Analysis in Climate Research (Cambridge University Press, Cambridge), pp. 494

Storch, H. von , E. Zorita and U. Cubasch (1993): Downscaling of global climate change estimates to regional scales, an application to Iberian rainfall in wintertime, J. Climate, 6, 1161-1171.

Trigo, R.M. and J.P. PAlutikof (2001): Precipitation scenarios over Iberia: a comparison between direct GCM output and different downscaling techniques, $\mathrm{J}$. Climate, 14, 4422-4446.
Ulbrich, U., M. Christoph, J.G. Pinto and J. Corte-Real (1999): Dependence of winter precipitation over Portugal on NAO and baroclinic wave activity, Int. J. Climatol., 19, 379-390

Velleman, P.F. and D.C. Hoaglin (1981): Applications, Basics, and Computing of Exploratory Data Analysis (Duxbury, Boston), pp. 354.

Vose, R.S., R.L. Schmoyer, P.M. Steurer, T.C. Peterson, R. HeIM, T.R. KARL and J.K. EISCHEID (1992): The Global historical climatologynetwork: long-term monthly temperature, precipitation, sea level pressure, and station pressure data, NDP-041, Carbon Dioxide Information Analysis Center, Oak Ridge National Laboratory, Oak Ridge, Tennessee (on line: http://cdiac.esd.ornl.gov/ghen/ ghen.html).

ZANGVIL, A. and P. DRUIAN (1990): Upper air trough axis orientation and the spatial distribution of rainfall over Israel. Int. J. Climatol., 10, 57-62

Zhang, X., X. Wang and J. Corte-Real (1997): On the relationships between daily circulation patterns and precipitation in Portugal, J. Geophys. Res., 102, 1349513507.

ZORITA, E., V. KHARIN and H. vON STORCH (1992): The atmospheric circulation and sea surface temperature in the North Atlantic area in winter: their interaction and relevance for Iberian precipitation, J. Climatol., 5, 1097-1108.

(received December 15, 2003; accepted March 4, 2004) 